\title{
Particle Choices and Collocation in Cameroon English Phrasal Verbs
}

\author{
Napoleon Epoge \\ Higher Teacher Training College (ENS) Yaounde, University of Yaounde I \\ PO box 47, Yaounde, Cameroon \\ E-mail: mcepoge@yahoo.fr
}

Doi:10.7575/aiac.alls.v.7n.1p.105

Received: 11/09/2015

URL: http://dx.doi.org/10.7575/aiac.alls.v.7n.1p.105

Accepted: 09/11/2015

\begin{abstract}
The meaning of some phrasal verbs can be guessed from the meanings of the parts (to sit down $=$ sit + down, run after $=$ run + after) and the meaning of some others have to be learned (to put up (a visitor) $=$ accommodate, to hold up $=$ cause delay or try to rob someone) due to their syntactic and semantic complexities. In this regard, the syntactic and semantic properties are expected to be the same in every English speaking context. Thus, this paper aims to explore the inputoriented syntactic and semantic properties of phrasal verbs in Cameroon English. Findings reveal that the syntactic property of some phrasal verbs undergoes innovative processes such as particle substitution (to round up a point), omission (to bite more than you can chew), and redundancy (to meet up with the requirements); while the semantic property undergoes the process of semantic extension (to came out with a pathetic story to justify ones absence from office; to come out with a wonderful strategy to curb corruption), and semantic shift (to put up with someone for one semester). This reveals that, in the New English context such as Cameroon, users resort to the domestication of the alien language as a functional and dominant paradigm to combat cultural imperialism and express new identity.
\end{abstract}

Keywords: Cameroon English, collocation, particle, phrasal verb, semantics, syntax

\section{Introduction}

The view of language as a system for meaning potential implies that language is specific to context and must be studied within the social and geographical contexts it operates. This is evidently true, as it is accepted widely, that living languages change over time and space. Consequently, the English language used in environments different from its origin would adjust and change to suit its new environments. Such indigenized varieties are spoken mainly as second languages in many ex-British colonies with multilingual populations such as Cameroon, Nigeria, and Ghana. The differences between the new varieties and the standard variety may be viewed from the aspects of phonology, syntax and semantics invoked naturally or otherwise to express new identities. To this end, this paper aims to examine innovations in particle choices and collocation in Cameroon English phrasal verbs. The paper is divided up into five phases: overview of phrasal verb literature, theoretical paradigm, methodology, results, and discussion of findings.

\section{Overview of phrasal verb literature}

A phrasal verb is a combination of a verb and one or two particles which together function as a single verb. The particle may be an adverb, a preposition or a word that can act as either an adverb or a preposition (Stephens, 2002). These are either spatial adverbs (e.g., aback, ahead, and away), prepositions (e.g., at, for, from), or words which in other contexts can act either as adverbs or as prepositions (e.g., by down, in). Hence, a phrasal verb is broadly construed as a structure which consists of a verb proper and a morphologically invariable particle that functions as a single unit both lexically and syntactically (Darwin and Gray, 1999; Quirk et al, 1985). This diverse combinations breeds varied phrasal verbs and meanings. The meanings are divided up into three sub-classes:

- the verb and the particle keep their individual lexical meanings (e.g., look over (inspect), set up (organize);

- the verb alone keeps its lexical meaning and the particle has an intensifying function (e.g., find out (discover), sweep up (sweep);

- the verb and the particle are fused into a new idiomatic combination, the meaning of which is not deducible from its parts (e.g., bring up (educate), come by (obtain), put off (postpone), turn up (appear, arrive), come in for (receive).

In such combinations, the adverbial lexical values of the particles have been lost and the entire verb-particle combination has acquired a new meaning. Therefore, Hall (2002) notes that phrasal verbs are used in three ways:

- to describe an action literally (e.g., He went out of the room);

- to intensify or emphasize an action (e.g., It has been pouring down all day);

- to act as a verb with a special meaning (e.g., Her daughter was run over while playing in the street). 
It is healthy to point out here that the particles, which carry the syntactic and semantic functions (Omar, 2005), are significant structural elements and essential discourse devices which constitute the basic components in producing written texts (Carmen, 2004). However, though the particles are cardinal in processing language in communication, acquiring their usage in English phrasal verbs is challenging to non-native learners of the language due to the syntactic and semantic complexities of phrasal verbs (McArthur, 1992; Crystal, 1995; Thrush, 2001; Hourany, 2002; Eastwood, 2006; Yasir, 2011). This is because preposition and adverb particles, in the English language, demonstrate varied meanings in which some of them are very challenging and need high cognitive and mental work from language users' part (Courtney, 1983; Dirven, 1993; Cuyckens and Radden, 2002; Eastwood, 2006). In view of the above-stated, Baker (1982) identifies and categorizes non-native learners of English difficulty with phrasal verbs in four areas: semantics (i.e., understanding what the expression means), structure (i.e., knowing what patterns the expression can follow), phonology (i.e., producing correct natural stress), and collocation (i.e., knowing with which particular group of words the expression can be used). In this connection, the present study is concerned with innovative particle choices and collocation patterns in Cameroon English phrasal verbs. Since no research endeavour has so far ventured into the examination of particle choices and collocation patterns in Cameroon English, there is paucity of organized knowledge in this area of research. This attempt may be considered as one of the few research attempts in an unexploited area.

\section{Theoretical Paradigm}

There are two main paradigms with regard to phrasal verbs interpretation: lexical-morphological interpretation and syntactic interpretation. The lexical-morphological interpretation holds that the particle and verb combine presyntactically and form a constituent that excludes the direct object (Olsen, 2000; McIntyre, 2001). In spite of the plausibility of this stipulation, it is noticed that the main problem, for a morphological analysis of phrasal verbs, is the violation of the principle of lexical integrity. Though the verb and the particle form a semantic unit that may take on an idiomatic meaning differently from prefixed words, the particle and the verb, although closely connected, do not completely fuse to form an inseparable complex word (Iacobini, 2009).

Alongside the lexical-morphological interpretation is the syntactic interpretation. The latter is anchored on two principal kinds of analyses: syntactic complex predicate approach and principled syntactic approach. The first, the syntactic complex predicate approach, holds that the verb and the particle form a phrasal constituent which enters the syntax as separate heads (Zeller, 2001). The second, principled syntactic approach, assumes that the particle predicates over the post-verbal NP in a resultative minimal predicate structure that possesses arguments and predicates, but no finite verb (Kayne, 1985, 1998; Den Dikken, 1995).

Beyond the above-stated modular model of Generative Grammar, Toivonen (2003) adopts a Lexical Functional Grammar approach. Toivonen (2003) posits that particles are lexically specified as non-projecting words, and that their adjunction to the verb is sanctioned by a specific phrase-structure rule. This stipulation corroborates Booij (2001, 2002b) claims that phrasal verbs are a case of "periphrastic word formation", that is, lexical items that can behave as complex words, even though they originate from a phrasal construction. Hence, he stipulates that phrasal verbs are "constructional idioms". The idea that there are constructional meanings which are independent of the particular lexical items that make up the sentence has been "the most noteworthy development in the area of the lexicon-syntax interface" (Zubizzareta and Oh, 2007:1) since the 1980s. What we gather from all these specifications is that collocation and semantic features are cardinal in syntactic analysis.

The term "collocation" denotes the way in which words are used together regularly. That is, it refers to the restrictions on how words can be used together. For instance, which preposition or adverb particles are used with particular verbs, or which verbs and nouns are used together. In English the verb "perform" is used with "operation", but not with "discussion" as exemplified below.

- The doctor performed the operation.

- *The committee performed a discussion.

- The committee held/had a discussion.

In these examples, the verb "perform" is used with (collocates with) "operation" (but not with discussion), and the verb "hold" and "have" collocate with "discussion".

Along with collocation is the semantic feature. The latter denotes the basic unit of meaning in a word. The meanings of words may be described as a combination of semantic features. For instance, the semantic feature, male, is part of the meaning of "father", but other features are needed to give the whole concept a sense of "father". Furthermore, the same feature may be part of the meaning of a number of words. For example, the word "movement" is part of the meaning of a whole group of verbs and nouns: run, jump, walk, gallop (Richards and Schmidt, 2002:477). This portrays that meaning plays an important part in grammatical analysis. These perspectives underlie the examination of the internal structure of phrasal verbs and the rules which govern them in Cameroon English.

\section{Methodology}

The data for this study was collected through a production test, reading of the end-of-training dissertations, recordings and field investigation. The production test, designed to assess the respondents' proficiency of phrasal verbs, consisted of fifteen contextualized phrasal verbs which were drawn from the students' English curricula courses. The test comprised of a multiple choice comprehension task (MCCT) and a gap test task (GTT). 
In the multiple choice comprehension task, the respondents were asked to choose an appropriate particle, from the list provided in the brackets at the end of each sentence, to fill in the blank so that the sentence is complete and expresses a complete thought (e.g. I came a vase exactly like yours in a Chinese shop (over, into, across). In the gap test task, respondents were asked to fill in each of the gaps provided with an appropriate adverb or preposition particle, to complete the sentence (e.g. The government has come with a wonderful strategy to curb corruption).

The test was administered to English Major Undergraduate and Postgraduate students of the Department of English, University of Yaounde I; and the Higher Teacher Training College (ENS) Bambili, University of Bamenda. The test lasted 30 minutes in each of the Levels chosen. After administering the test, a sample of 92 randomly selected scripts was considered for analysis. Consequently, the randomly selected scripts of 92 respondents served as the sampled population for this study. This sampled population, according to institution and academic level, is presented in the table below.

Table 1. Distribution of Respondents according to Academic Level and University

\begin{tabular}{llll}
\hline Academic Level & $\begin{array}{l}\text { University of } \\
\text { Yaounde I }\end{array}$ & $\begin{array}{l}\text { University of } \\
\text { Bamenda }\end{array}$ & Total \\
\hline Level 3 & $17(18.48 \%)$ & $15(16.30 \%)$ & $32(34.78 \%)$ \\
Level 4 & $15(16.30 \%)$ & $15(16.30 \%)$ & $30(32.61 \%)$ \\
Level 5 & $15(16.30 \%)$ & $15(16.30 \%)$ & $30(32.61 \%)$ \\
TOTAL & $47(51.09 \%)$ & $45(48.91 \%)$ & $92(100 \%)$ \\
\hline
\end{tabular}

The table above shows that 47(51.09\%) of the respondents were from the University of Yaounde I and 45(48.91\%) were from the University of Bamenda. This gives a total of ninety-two respondents as the sampled population. The data collected was analysed using a scoring scheme wherein a response that reflected the Standard British English (SBE) input-oriented feature specifications got a point and any other got no point. Furthermore, feature specifications, in the data provided, were identified, described, and analysed. The results of the respondents' performance are jointly presented in tables below.

Besides the production test, there was need to obtain data from free writing, most especially academic writing of the students, to corroborate the data provided by the production test. In this vein, some randomly selected end-of-training dissertations written by postgraduate students in the Department of English, University of Yaounde I, and Higher Teacher Training College (ENS) Bambili, University of Bamenda, were examined. Some data were also collected through recordings and field investigation. The recordings involved mainly the informal and formal conversations of university students as well as educated speakers of Cameroon English at different social events, conferences, and seminars. An impressive number of recurrent innovative phrasal verbs were identified, described and analysed. They have been taken into consideration in the discussion phase.

\section{Test Results}

The results in table 2 below show the general performance of the sampled population in the production test.

Table 2. Respondents' performance in the production of phrasal verbs

\begin{tabular}{llcc}
\hline Academic Level & SBE Parameter Settings & Other Parameter Settings & Total \\
\hline Level 3 & $118(24.58 \%)$ & $362(75.42 \%)$ & $480(100 \%)$ \\
Level 4 & $187(41.56 \%)$ & $263(58.44 \%)$ & $450(100 \%)$ \\
Level 5 & $226(50.22 \%)$ & $224(48.78 \%)$ & $450(100 \%)$ \\
TOTAL & $531(38.48 \%)$ & $849(61.52 \%)$ & $1380(100 \%)$ \\
\hline
\end{tabular}

As can be seen in the table above, the respondents provided 531(38.48\%) instances wherein the Standard British English input-oriented feature specifications were respected, and 849(61.52\%) instances wherein the respondents employed other parameter settings in their choice of the adverb and preposition participles to come up with phrasal verbs. To this end, they produced phrasal verbs such as:

1. The government has come out with a wonderful strategy to curb corruption. (for SBE "come up with", i.e., to suggest or think of an idea or plan that is positive; or to produce and discover something in response to a need or challenge).

2. Let me round up this point. (for SBE "round off", i.e., to complete an event or an activity in a pleasant or satisfactory way).

3. The plane is blown off by the terrorists. (for SBE "blown up", i.e., to destroy something or kill someone with a bomb). 
4. I came over a vase exactly like yours in a Chinese shop. (for SBE "come across", i.e., to meet by chance)

5. John did not meet up with the requirements to enroll for the course. (for SBE "meet", i.e., to fulfill, satisfy, or achieve)

6. Please, put off your phones. (for SBE "switch off", i.e., to turn off a piece of electrical equipment or be turned off)

7. Can you break up these figures and let me have the details? (for SBE "break down", i.e., to analyse).

8. I seem to spend most of my time running around for those kids. (for SBE "run around after", i.e., to do a lot of things for someone else, especially when they should be able to do more for themselves).

9. Firefighters have been called to put off the fire in the Mokolo market. (for SBE "put out", i.e., to extinguish or stop burning)

The changes inscribed in the way these particles are used are products of realities in new language speaking contexts such as Cameroon. This is because phrasal verbs are a feature of the "Germanic language family" and English belongs to this language family (Schmitt \& Siyanova, 2007). Consequently, learners who are not German or Scandinavian may be unfamiliar with these multi-word verbs and they may lack the strategies to deal with them. Hence, when non-native speakers of English, such as the respondents in this study, encounter difficulties of syntactic and semantic features in understanding and using phrasal verbs, due to their grammatical peculiarities, they dominantly choose particles that make them produce phrasal verbs that are communicatively comprehensible among themselves. However, as they move up the academic ladder, with much exposure to input, their understanding of the grammatical peculiarities of phrasal verbs is ameliorated as the graph below illustrates.

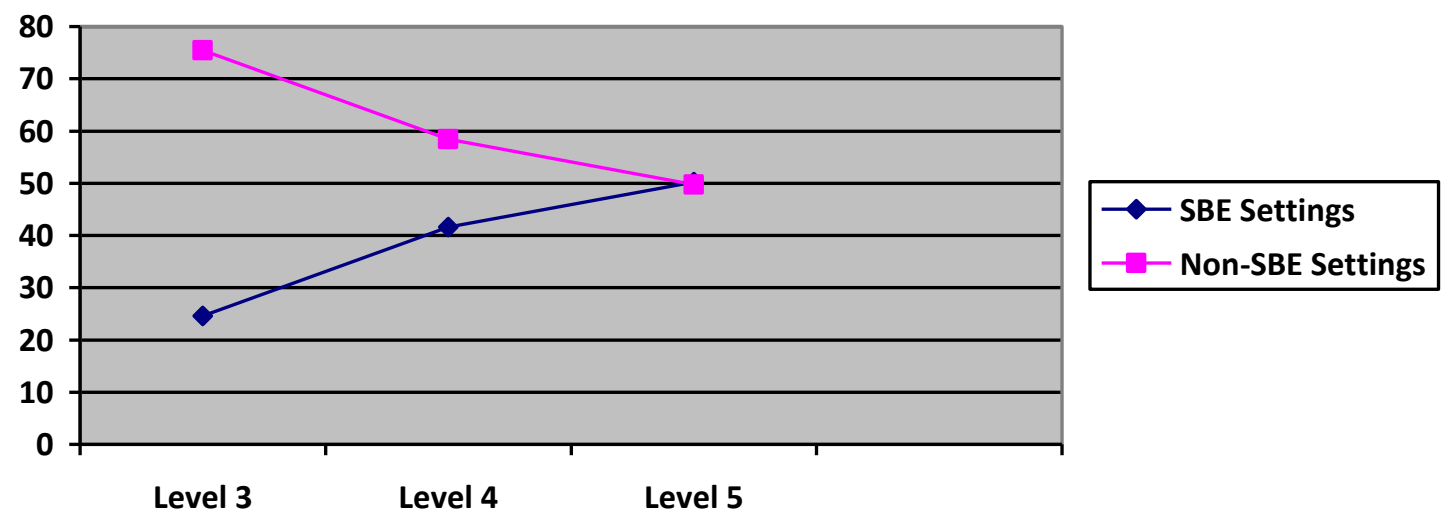

Figure 1. Respondents' performance in relation to level of education

The graph shows that respondents from Level Three produced the least number of instances 118(24.58\%); while those from Level Five produced the highest number of instances 226(50.22\%) in respecting the Standard British English input-oriented feature specifications. However, none of the groups showed a good mastery of the Standard British English input-oriented feature peculiarities. The majority of the instances they produced $847(61.52 \%)$ exhibited structural features which did not adhere to the Standard British English input-oriented feature specifications. In order to highlight this, the respondents' performances in the different syntactic and semantic peculiarities of phrasal verbs: verb + adverb + preposition (4.1), verb + adverb (4.2), and verb + preposition (4.3) are discussed below.

\section{1 verb + adverb + preposition}

One of the syntactic peculiarities of phrasal verbs is that they may be composed of a verb, and an adverb and a preposition particle. The lexical collocation of the verb and these particles builds up the grammatical peculiarity of the phrasal verb concerned. The data provided exhibited feature specifications that do not tie with the lexical and collocation features of the Standard British English input-oriented feature specifications. The results of the respondents' performance are presented in the table below.

Table 3. Respondents' performance in the production of three-part phrasal verbs $(n=3)$

\begin{tabular}{llll}
\hline Academic Level & SBE Parameter Settings & Other Parameter Settings & Total \\
\hline Level 3 & $27(28.13 \%)$ & $69(71.87 \%)$ & $96(100 \%)$ \\
Level 4 & $36(40 \%)$ & $54(60 \%)$ & $90(100 \%)$ \\
Level 5 & $39(43.33 \%)$ & $51(56.67 \%)$ & $90(100 \%)$ \\
TOTAL & $102(36.96 \%)$ & $174(63.04 \%)$ & $276(100 \%)$ \\
\hline
\end{tabular}


Statistics in the table show that 102(36.96\%) instances provided by the respondents tie with the Standard British English input-oriented feature specifications as in (10).

10. She thinks they look down on her because she didn't go to university.

Furthermore, respondents provided 174(63.04\%) responses whereby they employed Non-Standard British English feature specifications as in (11).

11. The government has come out with a wonderful strategy to curb corruption.

In this structure, the respondents were expected to come up with the phrasal verb "come up with" to express the notion of suggesting or thinking of an idea that is positive. However, in the majority of the responses they provided, they came up with the phrasal verb "come out with" (to say something usually unexpected, surprising, false or hard to believe) to mean "to think and suggest an idea, a plan or a solution that is positive; or to produce and discover something in response to a need or challenge). With this, it can be deduced that the phrasal verbs "to come up with" and "to come out with" are synonymous in Cameroon English usage. It has also shown that the phrasal verb "to come out with" has undergone semantic extension in the learners' grammar. In the same vein, the structure such as the one in (12) were recurrent in the data provided.

12. Catherine will put up with me for one semester.

In (12), the phrasal verb "to put up with (somebody/something), which means to accept or continue to accept an unpleasant situation in Standard British English as in "John is moody - I don't know why Mary puts up with him" is used in the learners' grammar to express the idea of providing someone with a place to stay temporary. The phrasal verb "to put somebody up" which means to provide someone with a place to stay temporary as in "Deborah is putting me up for a weekend" was expected. Since no respondent provided the expected phrasal verb, it could be concluded that the phrasal verb "to put somebody up" is non-existent in the respondents' grammar. However, the phrasal verb "to put up with", which means to accept or continue to accept an unpleasant situation in Standard British English has undergone semantic shift in the learners' grammar to express the idea of providing someone with a place to stay temporary.

5.2 verb + adverb

A phrasal verb may be composed of a verb and an adverb particle. Hence, the semantic and lexical collocation of the verb and the particle is construed by the grammatical peculiarity of the phrasal verb concerned. However, a majority of the responses provided in the data exhibited lexical and semantic collocation features which do not tie with the Standard British English input-oriented feature specifications. Thus, the respondents came up with novel phrasal verbs. The table below sums up the statistics of their performance.

Table 4. Respondents' performance in the production of verb + adverb phrasal verbs $(n=7)$

\begin{tabular}{lllc}
\hline Academic Level & SBE Parameter Settings & Other Parameter Settings & Total \\
\hline Level 3 & $56(25 \%)$ & $168(75 \%)$ & $224(100 \%)$ \\
Level 4 & $91(43.33 \%)$ & $119(56.67 \%)$ & $210(100 \%)$ \\
Level 5 & $112(53.33 \%)$ & $98(46.67 \%)$ & $210(100 \%)$ \\
TOTAL & $259(40.22 \%)$ & $385(59.78 \%)$ & $644(100 \%)$ \\
\hline
\end{tabular}

The scores in the table above show that the respondents provided 259(40.22\%) instances which respected the Standard British English input-oriented feature specifications. In the same vein, they produced 385(59.78\%) instances in which other parameter settings had been employed as in (13) and (14).

13. Let me round up this point' (for SBE 'round off').

14. The plane is blown off by the terrorists" (for SBE 'blown up').

5.3 verb + preposition

A phrasal verb may be composed of a verb and a preposition particle. An analysis of the responses provided in the data revealed that the lexical and semantic collocation features of most of the afore-mentioned type of phrasal verbs do not tie with the Standard British English input-oriented feature specifications. The table below sums up the performance of the respondents.

Table 5. Respondents' performance in the production of verb + preposition phrasal verbs $(\mathrm{n}=5)$

\begin{tabular}{llll}
\hline Academic Level & SBE Parameter Settings & Other Parameter Settings & Total \\
\hline Level 3 & $35(21.88 \%)$ & $125(78.12 \%)$ & $160(100 \%)$ \\
Level 4 & $60(40 \%)$ & $90(60 \%)$ & $150(100 \%)$ \\
Level 5 & $75(50 \%)$ & $75(50 \%)$ & $150(100 \%)$ \\
TOTAL & $170(36.96 \%)$ & $290(63.04 \%)$ & $460(100 \%)$ \\
\hline
\end{tabular}


The table above shows that the respondents provided 170 (36.96\%) instances which respected the Standard British English lexical and semantic collocation features of the phrasal verbs examined. Though this percentage, it is feasibly clear that a greater majority of the responses 290(63.04\%) did not meet the Standard British English specifications. The phrasal verbs produced are flavoured and coloured to suit the respondents' sociolinguistic background as in (15), (16), and (17).

15. I came over a strange man in my village today. (for SBE 'come across', i.e., to meet by chance)

16. You have only had a slight cold. You will get off it in a day or two. (for SBE 'get over', i.e., to recover from)

17. It is an offer that you wouldn't get again so I should jump for it if I were you. (for SBE 'jump at', i.e., to accept immediately).

\section{Discussion}

The analysis of the results of the data collected shows that respondents adopt innovative feature specifications such as the substitution of the Standard British English adverb particle for another adverb particle (5.1), substitution of the Standard British English preposition particle for another preposition particle (5.2), occurrence of redundant particles (5.3), omission of particle (5.4), omission of verb (5.5), semantic extension (5.6), and semantic shift (5.7).

\subsection{Substitution of the SBE adverb particle for another adverb particle}

The learners' grammar is characterized by phrasal verbs wherein the Standard British English input-oriented adverb particles are substituted for other adverb particles as exemplified below.

18. Did you know that Jonathan had gone out with his sister-in-law? (for SBE 'gone off with', i.e., to leave a partner in order to have a sexual or romantic relationship with someone else)

19. I picked up the book and it came out in my hands. (for SBE 'come apart', i.e., to separate into several pieces)

20. Let me round up this point. (for SBE 'round off', i.e. to complete an event or activity in a pleasant or satisfactory way)

21. The plane is blown off by the terrorists. (for SBE 'blown up', i.e., to destroy something or kill someone with a bomb, or to be destroyed or killed by a bomb);

22. The sound of his footsteps gradually died out. (for SBE 'died away', i.e., it becomes reduced until it stops existing or disappears)

23. Someone is putting it out that Rosemary is pregnant. (for SBE 'putting it about/around', i.e., to tell a lot of people something that is not true)

24. Bullies often back up when you stand up for them. (for SBE 'back down', i.e., become less aggressive)

25. I do wish you'd stop going out with my car without asking me beforehand. (for SBE 'going off with', i.e., to take something without getting permission from the owner first)

26. John suggests we break off now and meet again at five o'clock. (for SBE 'break up', i.e., stop a speech or conversation)

27. Would you mind putting your cigarette off, please? (for SBE 'putting your cigarette out', i.e., to stop burning)

28. Can you break up these figures and let me have the details? (for SBE 'break down', i.e., analyse);

29. The question of salary increase will come out at the next general meeting. (for SBE 'come up', i.e., to be mentioned or talked about).

30. She is running about with Michael and his friends these days. (for SBE 'run around with', i.e., to spend a lot of time with someone)

The exemplifications above reveal one of the changes inscribed in the way English phrasal verbs are produced in a nonnative setting. These changes or innovations are products of reality in a new language speaking context such as Cameroon whereby the English language learners/speakers come up with lexical and syntactic structures that are communicatively comprehensible only among themselves. The next innovative process noticeable in the data provided is the substitution of the Standard British English preposition particle for another preposition particle.

\subsection{Substitution of the SBE preposition particle for another preposition particle}

The substitution of the Standard British English preposition particle for another preposition particle is one of the characteristic features identified in the respondents' grammar as exemplified below.

31. I came over a strange man in my village today. (for SBE 'Come across', i.e., to meet by chance)

32. She jumps at her children instantly if they are disobedient. (for SBE 'jump on', i.e., to criticize someone as soon as they have done something or said something you disagree with)

33. You have only had a slight cold. You will get off it in a day or two. (for SBE 'get over', i.e., to recover from)

34. Mr John's version of events does not accord to his witnesses statements. (for SBE 'accord with', i.e., to be the same as or to agree with)

35. Deborah's happiness consists of watching television and reading magazines. (for SBE 'consists in', i.e., to have something as a main and necessary part or quality. It is good to note here that there is also 'consist of' but 
it means to be made of or formed from something e.g. "The team consists of four Europeans and seven Africans".)

36. It is an offer that you wouldn't get again so I should jump for it if I were you. (for SBE 'jump at', i.e., to accept immediately)

37. While she was pregnant, her husband waited for her hand and foot. (for SBE 'wait on', i.e., to do something for someone, to help)

38. If there isn't enough soup to go around just put some hot water into it. (for SBE 'go round', i.e., enough for everyone in a group of people)

Speakers of English in Cameroon come up with these changes in order to make the phrasal verbs comprehensible among themselves. They feel that the Standard British English input-oriented preposition particle attached to the verb, to form a phrasal verb, does not enable the phrasal verb to convey its meaning succinctly. Besides the above innovative process, occurrence of redundant particles is feasible in the data collected.

\subsection{Occurrence of redundant particle(s)}

Communicational redundant particles which are supposed to be omitted do occur in the learners' grammar. Some of these innovative phrasal verbs are:

39. John did not meet up with the requirements to enroll for the course. (for SBE 'meet', i.e., to fulfill, satisfy)

40. I'd rather wait in for the storm than drive home immediately. (for SBE 'wait out', i.e., to wait until something unpleasant has ended)

These additions are made by L2 learners/speakers to make the phrasal verbs succinctly meaningful. They feel that there is something lacking to make these phrasal verbs complete in thought and structure. Another innovative process feasible in the data provided is the omission of particle.

\subsection{Omission of particle}

One of the features specifications identified in the learners' grammar is the recurrent omission of the particle in some phrasal verbs. This is exemplified by the tokens below.

41. Jacob grew in the village. (for SBE 'grow up')

42. The AES-SONEL will cut the electricity if you do not pay the bill. (for SBE 'cut off', i.e., to stop supply)

43. Our deepest sympathies go to her husband and children. (for SBE 'go out to', i.e., to think and feel sorry for someone)

44. I'll be home after midnight, so don't wait for me. (for 'wait up', i.e., to not go to bed at night because you are expecting someone to arrive)

45. Mary's already agreed, but it's going to be harder persuading Joseph to go with it. (for SBE 'go along with", i.e., to support or agree with)

46. She agonized for days whether she should take the job. (for SBE 'agonized over/about', i.e., to spend time worrying and trying to make a decision about it; e.g. 'She agonized for days over whether she should take the job).

47. Fill the blanks with appropriate prepositions. (for SBE 'fill in', i.e., to write the necessary information on an official document)

48. Volunteers would fill for teachers in the event of a strike. (for 'fill in for', i.e., to do someone else's work for them because they cannot or will not do it themselves)

The omission of the Standard British English input-oriented particles in the construction of phrasal verbs by these L2 learners/speakers is a testimony of language change and identity construction as it is exported to another context. This is done to enable the phrasal verbs to fit within the cultural and the linguistic atmosphere of the new users. Another feature noticeable in the data that contributes in building this socio-cultural and linguistic atmosphere is the omission of the verb.

\subsection{Omission of the verb}

Omission of the verb is one of the characteristic features in the learners' grammar. English language learners/speakers in Cameroon recurrently come up with structures wherein only the particle of a phrasal verb is used. This is exemplified by the tokens below.

\section{Please, off your phones. (for SBE 'switch off')}

50. Can you on the television for us? (for SBE 'switch on")

As the examples above illustrate, there are varied ways in which L2 learners/speakers of English in Cameroon come up with innovative English phrasal verbs that are appealing and comprehensible only to them. Not only do phrasal verbs undergo a number of syntactic innovation processes, they are also subjected to semantic innovation processes such as semantic extension and semantic shift. 
One of the characteristic innovative features in the semantics of English phrasal verbs, in the Cameroon variety of English, is semantic extension. For instance, the phrasal verb "to come out with" plays two roles in the learners' grammar: (i) it is used to express the notion of suggesting or thinking of an idea that is positive or of producing and discovering something in response to a need or challenge; and (ii) it is equally used to express something surprising, suddenly and unexpectedly, in order to deceive. The tokens below amply illustrate this semantic extension.

51. Evelyn has come out with a brilliant solution.

52. The researcher came out with a theory that is being used abroad.

53. The Choristers have come out with a beautiful song to thrill the audience.

54. The government has come out with a wonderful strategy to curb corruption.

55. She's come out with some amazing scheme to double her income.

56. Catherine came out with a pathetic story to justify her absence from office.

57. You always come out with such lies when you are cornered.

In view of this, we could come to the conclusion that the phrasal verbs "to come up with" and "to come out with" are synonymous in Cameroon English usage. This is as a result of the semantic extension that the phrasal verb "to come out with" has undergone in the learners" grammar in also denoting "suggesting or thinking of an idea that is positive or producing and discovering something in response to a need or challenge" as seen in 51 -55 above.

\subsection{Semantic shift}

The phrasal verb "to put somebody up" which means to provide someone with a place to stay temporary is non-existent in respondents' grammar. Instead, the phrasal verb "to put up with is used to express this idea as in (56).

58. Catherine will put up with me for one semester.

This clearly shows that the phrasal verb "to put up with" has undergone semantic shift in the respondents' grammar. It is not used to express its original meaning of "to accept or continue to accept an unpleasant situation" as in "John is moody - I don't know why Mary puts up with him”, but it is instead used to express the idea of providing someone with a place to stay temporary.

In the same light, the phrasal verb "to put off" which means in SBE to decide or arrange to delay an event or activity until a later time or date (to postpone) as in "The meeting has been put off for a week" is used in the learners' grammar to express the idea of 'turning off a piece of electrical equipment or being turned off' as in (57).

59. Please, put off your phones. (for SBE 'switch off').

As exemplified above, the phrasal verbs "to put up with" and "to put off" have undergone semantic shift in the variety of English spoken in Cameroon.

\section{Conclusion}

This paper has examined the use of adverb and preposition particles in the construction of some phrasal verbs by ESL learners/users Cameroon. This is done through an analytical, descriptive and interpretative approach to the data provided in the syntactic structures of this linguistic phenomenon. After a thorough perusal and analysis of the data, the results show that learners/users encounter problems of semantics and collocation features in understanding and using phrasal verbs due to their grammatical peculiarities. Consequently, they dominantly choose particles that made them produce phrasal verbs such as "The government has come out with a wonderful strategy to curb corruption" and "Let me round up this point" which are communicatively comprehensible only among themselves. Hence, the learners' grammar is characterized by substitution of the Standard British English input-oriented adverb and preposition participles of phrasal verbs for some other adverbs and preposition particles; omission of particles; presence of communicational redundant particles which are supposed to be omitted as well as semantic extension and shift of phrasal verb usage. The paper concludes that changes inscribed in the way these particles are used are products of realities in new language speaking context whereby users of the English language resort to the domestication of the alien language as a functional and dominant paradigm to combat cultural imperialism and express new identity.

\section{References}

Baker, A. (1982). English to Get on with: Practice in Phrasal/ Prepositional Verbs. London: Heinemann.

Booij, G. (2001). From Syntax to Morphology: Particle Verbs and Grammaticalization. In Schaner-Wolles, C., Rennison, J., and Neubarth, F. (eds.). Naturally! Linguistic Studies in Honour of W. U. Dressler. Torino: Rosenberg and Sellier, 59-65.

Booij, G. (2002). Separable Complex Verbs in Dutch: A Case of Periphrastic Word Formation. In Dehé Nicole et al. (eds.). 21-41.

Carmen, A. (2004). Some Fundamental Issues in the Semantic Analysis of Prepositions. Estudios Ingleses de la Universdad Complutense, 13.

Courtney, R. (1983). Longman Dictionary of Phrasal Verbs. London: Longman. 
Cruse, A. (2006). A Glossary of Semantics and Pragmatics. Edinburgh: Edinburgh University Press.

Cuyckens, H., and Radden, G. (ed.) (2002). Perspectives on Prepositions. Tübingen: Niemeyer.

Crystal, D. (1995). Cambridge Encyclopedia of the English Language. Cambridge: Cambridge University Press.

Darwin, C. and Gray, L. (1999). Going after the Phrasal Verb: An Alternative Approach to Classification. TESOL Quarterly, 33, 65-83.

Den Dikken, M. (1995). Particles on the Syntax of Verb-Particle, Triadic, and Causative Constructions. Oxford: Oxford University Press.

Dirven, R. (1993). Dividing up Physical and Mental Space into Conceptual Categories by Means of English Prepositions. In Zelinsky-Wibbelt, The Semantics of Prepositions: From Mental Processing to Natural Language Processing, 73-97. http://dx.doi.org/10.1515/9783110872576.73

Eastwood, J. (2006). Oxford Practice Grammar with Answers. Oxford: Oxford University Press.

Hall, P. (2002). Phrasal Verbs: English in Valencia. http://ralenciaenglish.netfirms.com/phrasals00htm

Hourany, Q. (2002). Syntactic and Semantic Problems in Translating English Phrasal Verbs to Arabic. MA Thesis, Yarmouk University, Irbid-Jordan.

Iacobini, C. (2009).The Role of Dialects in the Emergence of Italian Phrasal Verbs. Morphology, 19(1), 15-44.

Kaminska, P. (2001). Keywords for Phrasal Verbs. Modern English Teacher, 10(2), 59-61.

Kayne, R, (1985). Principles in Particle Constructions. In Guéron, J., H-G. Obenauer, and J-Y. Pollack, (eds.). Grammatical Representations. Dordrecht: Foris, 101-140.

Kayne, R. (1998). Overt vs. Covert Movement. Syntax, 1, 128-191.

Kolln, M. and Funk, R. (1998). Understanding English Grammar, $5^{\text {th }}$ (ed.). Boston: Allyn and Bacon.

McArthur, T. (1992). The Long-Neglected Phrasal Verb. English Today, 5(2), 38-44.

McIntyre, A. (2001). German Double Particles as Preverbs: Morphology and Conceptual Semantics. Tübingen: Stauffenburg.

Olsen, S. (2000). Against Incorporation. In Dölling, J. and T. Pechmann (eds.). Linguistische Arbeitsberichte, 74, 149172.

Omar, M. (2005). Baiaan Al-Lazim wa Al- Mutaadie. Al-Turath Al-Arabi. (Vol 99-100). Arab Union, Damascus, Syria.

Quirk, R., Greenbaum, S., Leech, G., and Svartvik, J. (1985). A Comprehensive Grammar of English Language. New York: Longman.

Richards, J. and Schmidt, R. (2002). Longman Dictionary of Language Teaching and Applied Linguistics. London: Longman.

Schmitt, N. and Siyanova, A. (2007). Native and Nonnative Use of Multi-word VS. One-word Verbs. IRAL, 45, 119139.

Stephens, A. (ed.) (2002). The English Phrasal Verb. North Carolina: University of North Carolina Press.

Thomson, A. and Martinet, A. (2009). A Practical English Grammar. Oxford: Oxford University Press.

Thrush, A. (2001). Plain English? A Study of Plain English Vocabulary and International Audiences. Technical Communication: Journal of the Society for Technical Communication, 48(3), 289-96.

Toivonen, I. (2003). Non-Projecting Words. A Case Study of Swedish Particles. Dordrecht: Kluwer.

Yasir, M. (2011). Semantic and Syntactic Problems in Comprehending English Phrasal Verbs. Tikrit University Journal for Humanities, 18(7), 17-43.

Zeller, J. (2001). Particle Verbs and Local Domains. Amsterdam/Philadelphia: John Benjamins.

Zubizzareta, M. and Oh, E. (2007). On the Syntactic Composition of Manner of Motion. Cambridge, MA: Michigan Institute of Technology Press. 